Article

\title{
Use of Linear Free Energy Relationships (LFERs) to Elucidate the Mechanisms of Reaction of a $\gamma$-Methyl- $\beta$-alkynyl and an ortho-Substituted Aryl Chloroformate Ester
}

\author{
Malcolm J. D'Souza ${ }^{1, *}$, Jaci A. Knapp ${ }^{1}$, Gabriel A. Fernandez-Bueno ${ }^{1}$ and Dennis N. Kevill ${ }^{2, *}$ \\ 1 Department of Chemistry, Wesley College, 120 N. State Street, Dover, DE 19901, USA; \\ E-Mails: jaci.knapp@email.wesley.edu (J.A.K.); gabriel.fernandez@email.wesley.edu (G.A.F.-B.) \\ 2 Department of Chemistry and Biochemistry, Northern Illinois University, DeKalb, IL 60115, USA \\ * Authors to whom correspondence should be addressed; E-Mails: dsouzama@wesley.edu (M.J.D.); \\ dkevill@niu.edu (D.N.K.); Tel.: +1-302-736-2528 (M.J.D.); +1-815-753-6882 (D.N.K.); \\ Fax: +1-302-736-2301 (M.J.D.); +1-815-753-4802 (D.N.K.).
}

Received: 20 December 2011; in revised form: 5 January 2012 / Accepted: 5 January 2012 / Published: 10 January 2012

\begin{abstract}
The specific rates of solvolysis of 2-butyn-1-yl-chloroformate (1) and 2-methoxyphenyl chloroformate (2) are studied at $25.0{ }^{\circ} \mathrm{C}$ in a series of binary aqueousorganic mixtures. The rates of reaction obtained are then analyzed using the extended Grunwald-Winstein (G-W) equation and the results are compared to previously published G-W analyses for phenyl chloroformate (3), propargyl chloroformate (4), p-methoxyphenyl choroformate (5), and $p$-nitrophenyl chloroformate (6). For 1, the results indicate that dual side-by-side addition-elimination and ionization pathways are occurring in some highly ionizing solvents due to the presence of the electron-donating $\gamma$-methyl group. For $\mathbf{2}$, the analyses indicate that the dominant mechanism is a bimolecular one where the formation of a tetrahedral intermediate is rate-determining.
\end{abstract}

Keywords: solvolysis; nucleophilicity; ionizing power; $\gamma$-Methyl- $\beta$-alkynyl chloroformate; 2-butyn-1-yl-chloroformate; aryl chloroformate; 2-methoxyphenyl chloroformate; Grunwald-Winstein equation; Linear Free Energy Relationships (LFERs) 


\section{Introduction}

$\gamma$-Methyl- $\beta$-alkynyl and mono substituted phenyl chloroformate esters such as 2-butyn-1-ylchloroformate (1) and 2-methoxyphenyl chloroformate (2) shown in Figure 1, have found use in the preparation of symmetrical urea's that have patented herbicidal control applications [1,2] against certain weeds, fungi, and bacteria. With the recent introduction of novel synthetic methodology [3-5], the interest in the synthetic utility of such alkynyl and aryl esters is further enhanced due to their supplemental increased use in pharmaceutical formulations.

Figure 1. Molecular structures of 2-butyn-1-yl chloroformate (1), 2-methoxyphenyl chloroformate (2), phenyl chloroformate (3), propargyl chloroformate (4), 4-methoxyphenyl chloroformate (5), and $p$-nitrophenyl chloroformate (6) are shown where the $\mathrm{C}=\mathrm{O}$ is syn with respect to the alkynyl or aryl moiety; i.e., the halogen atom is in a trans position with respect to the alkynyl or aryl group.

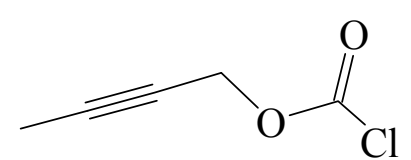

1

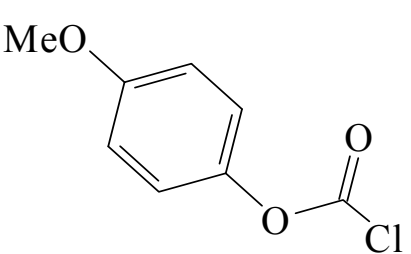

5<smiles>COc1ccccc1OC(=O)Cl</smiles>

2

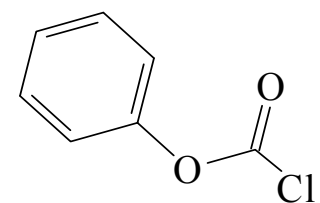

3<smiles>C#CCOC(=O)Cl</smiles>

4

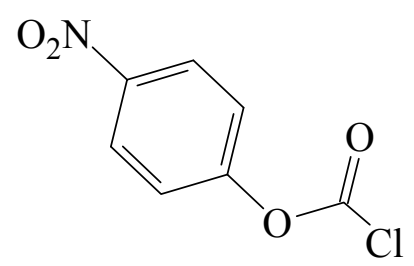

6

Linear free energy relationships (LFERs) [6-8] such as the Grunwald-Winstein (G-W) equations (Equations 1 and 2) [9,10] are often used to correlate [11,12] the specific rates of solvolysis of organic substrates to the solvent ionizing power [13-17] and solvent nucleophilicity values [18-20]. To commemorate the sixtieth anniversary of the original Grunwald-Winstein equation (Equation 1) [9] we documented [12] the utility of these G-W LFERs (Equations 1 and 2) in the analysis of a variety of organic compounds including a collection of chloroformate esters. Since this comprehensive review, several additional papers [21-43] have appeared; some corroborating the results obtained using Equations 1 and 2 [12] and proving that these LFERs are very successful in the elucidation of the solvolysis mechanisms for an assortment of acid chlorides.

$$
\begin{gathered}
\log \left(k / k_{o}\right)=m Y_{\mathrm{X}}+c \\
\log \left(k / k_{o}\right)=I N_{\mathrm{T}}+m Y_{\mathrm{X}}+c
\end{gathered}
$$

In the Grunwald-Winstein Equations 1 and 2, $k$ and $k_{o}$ are the specific rates of solvolysis of a substrate in a given solvent and in the standard solvent ( $80 \%$ ethanol), respectively, $m$ represents the sensitivity to changes in the solvent ionizing power $Y_{\mathrm{X}}$ (based on the solvolysis of 1- or 2-adamantyl derivatives) [13-17], $l$ is the sensitivity to changes in solvent nucleophilicity $N_{\mathrm{T}}$ (based on the solvolysis of $S$-methyldibenzothiophenium ion) [18-20], and $c$ is a constant (residual) term. 
For substrates that ionize via anchimeric assistance $\left(k_{\Delta}\right)$, or where conjugation allowed delocalization of an adjacent $\pi$-system, we proposed [44,45] adding an additional term, the aromatic ring parameter $I$, to Equations 1 and 2, to give Equations 3 and 4. In Equations 3 and 4, $h$ represents the sensitivity of solvolyses to changes in the aromatic ring parameter $I$.

$$
\begin{gathered}
\log \left(k / k_{o}\right)=m Y_{\mathrm{X}}+h I+c \\
\log \left(k / k_{o}\right)=I N_{\mathrm{T}}+m Y_{\mathrm{X}}+h I+c
\end{gathered}
$$

The solvolysis of substituted phenyl chloroformates [11,12,22,24,46-55], including the effects of aminolysis [56,57] and micellar aggregates [58-60] on rates of reaction, has been extensively studied in a wide variety of solvents. A thorough multiple regression analysis employing Equation 2 using various subsets of solvolytic rate data for phenyl chloroformate (3) in 49 solvents of widely varying nucleophilicity and ionizing power values, resulted in the proposal $[12,50,54]$ that 3 solvolyzes by an addition-elimination pathway with the addition step being rate-determining. Using Equation 2, the sensitivity values for 3 of 1.66 obtained for $l$ and 0.56 obtained for $m$, are now taken [12,21,22-26, $28-39,41,42,50,54]$ as typical values that are to be expected for solvent attack at an $\mathrm{sp}^{2}$ hybridized carbonyl carbon and involving the rate-determining formation of a tetrahedral intermediate (Scheme 1).

Scheme 1. Stepwise addition-elimination mechanism through a tetrahedral intermediate for phenyl chloroformate (3).
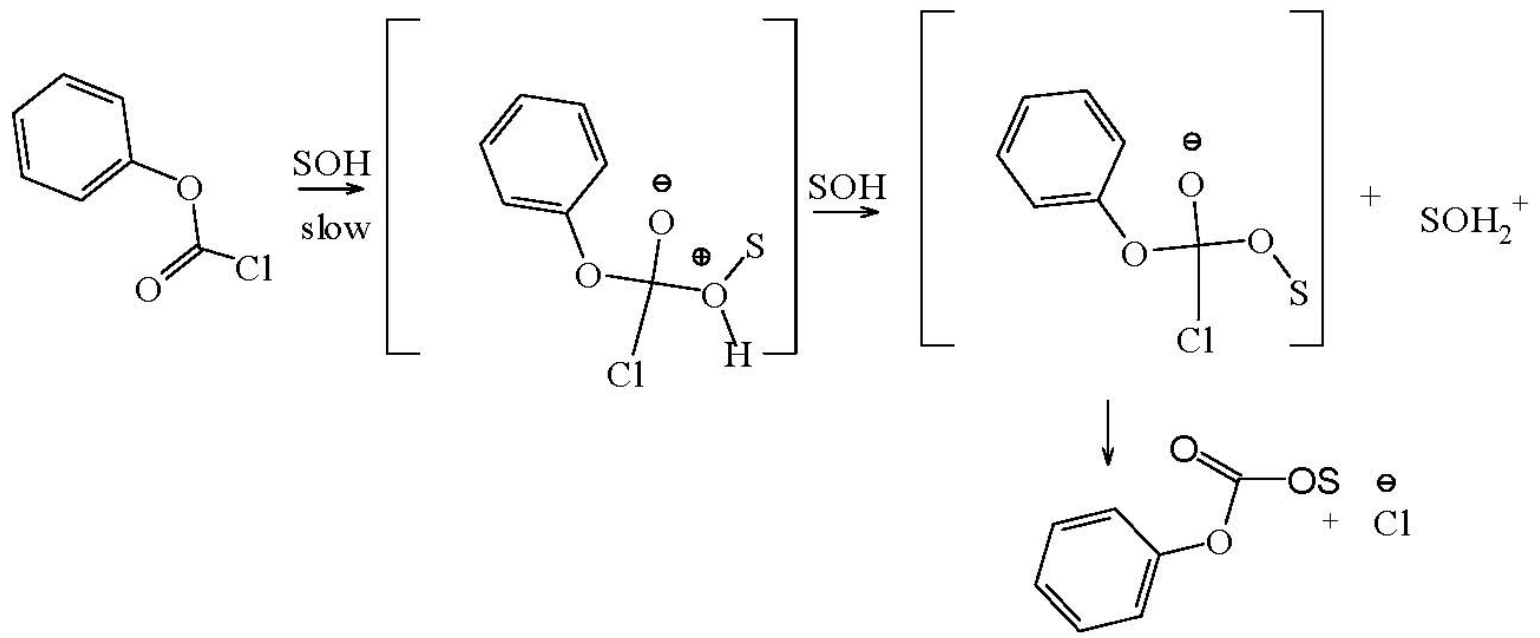

Recently we showed [35] that the inductive ability of the alkynoxy group in propargyl chloroformate (4) when compared to that of the phenoxy group in phenyl chloroformate (3) is reduced, as the alkynyl group is pushed out of the plane of the ester oxygen due to the presence of the additional carbon between the alkyne and the ester oxygen in $\mathbf{4}$. Additionally, we demonstrated [35] that $\mathbf{4}$ and $\mathbf{3}$ solvolyze by a similar bimolecular addition-elimination pathway with a rate-determining addition step in a variety of solvents including those with appreciable fluoroalcohol content. On the other hand, the former war gas isopropenyl chloroformate, was shown [37] to exhibit a superimposed unimolecular ionization $\left(\mathrm{S}_{\mathrm{N}} 1\right)$ mechanism in the strongly hydrogen-bonding 1,1,1,3,3,3-hexafluoro-2-propanol (HFIP) and 97\% 2,2,2-trifluoroethanol (TFE) mixtures with water.

It has been well documented $[10,12,32,45,61,62]$ in LFER analyses such as when using Equations $2-4$, that the inclusion of mixtures of fluoroalcohols is important to avoid multicollinearity effects 
when studying substrates like chloroformate esters [54,55]. We recently demonstrated [55] that the inclusion of additional highly ionizing 2,2,2-trifluoroethanol (TFE) and 1,1,1-3,3,3-hexafluoro-2propanol (HFIP) mixtures decreased the $h$ value of $p$-methoxyphenyl chloroformate (5) from 0.85 reported [54] for 31 solvents to 0.29 for 44 solvents [55]. The latter aromatic ring parameter number was also associated with a large probability $(0.114)$ that the $h$ term was statistically insignificant [55].

We previously compared [24] the Grunwald-Winstein (Equation 2) analyses obtained for 3 [12,50,54], 5 [54,55], and p-nitrophenyl chloroformate (6) [24] in 38 common solvents and determined $l$ values of $1.59,1.58$, and 1.69 , and $m$ values of $0.54,0.57$, and 0.46 respectively. Other groups $[11,48,53,63]$ have rightly stressed the importance of general-base catalysis occurring in the solvolyses of these three aryl chloroformates which was indicated by large observable kinetic solvent isotope effects (KSIEs) in methanol and methanol-d ( $\left.k_{\mathrm{MeOH}} / k_{\mathrm{MeOD}}\right)$. In an identical set of solvents, the observed $l / m$ ratios of 2.94 for $3,2.77$ for 5 , and to 3.67 for $\mathbf{6}$ implies an earlier transition-state for 6 due to the presence of the strongest inductive interaction because of the $p$-nitro group and a decrease in the importance of general base catalysis in going from 6 to 3 to 5 [24].

Very recent studies of carbamoyl chlorides using Equation 2 proposed ionization reactions for 4-morpholinecarbonyl chloride (7) [64] and 1-piperidincarbonyl chloride [65]. A little over a year ago, in a personal communication to Koo $[64,65]$ it was pointed out that he had overlooked our previous manuscript [66] published about 15 years earlier detailing the application of Equation 2 to the solvolyses of 4-morpholinecarbonyl chloride (7). Our work was at $25.0{ }^{\circ} \mathrm{C}$ [66], and the six more recently reported measurements at the same temperature [64] are in very good agreement. Also, the $l$ and $m$ values of 0.71 and 0.65 obtained for 7 are in excellent agreement with our earlier determined values of 0.74 and 0.66 . The $1 / \mathrm{m}$ ratio of 1.12 obtained [66], conforms to the expected range of the other carbamoyl esters [12] and implies a strong nucleophilic solvation effect at the developing carbamoyl carbocation $[12,66]$. The reason that the Koo group $[64,65]$ continue to overlook our work is probably because we named compound 7 as 4-(chloroformyl)morpholine (from the Aldrich catalog); which is a synonym [67] for 4-morpholinecarbonyl chloride.

As shown in Figure 1, 2-butyn-1-yl chloroformate (1) and propargyl chloroformate (4) differ only due to the presence of an adjoining methyl group on the $\beta$-triple bond in $\mathbf{1}$. In order to investigate whether the electron supplying effect of this $\gamma$-methyl group will have an additive influence on the solvolytic transition state, we have studied the solvolyses of $\mathbf{1}$ in eighteen binary organic-aqueous solvents with very different nucleophilic and ionizing abilities. Additionally in this article, we have analyzed the effect of the presence of a methoxy group in the 2-position in 0 -methoxyphenyl chloroformate (2) in seventeen solvents, and compared this data to those earlier obtained for the presence of a methoxy group in the 4 position in $p$-methoxyphenyl chloroformate (5) in identical solvents. To further analyze substituent effects, we have compared the solvolysis rates of $\mathbf{2}$ with the previously published compilation of rate data for phenyl chloroformate (3) and p-nitrophenyl chloroformate (6).

\section{Results and Discussion}

The experimental first-order specific rate constants that are listed in Table 1 were obtained for 2-butyn-1-yl chloroformate (1) in 18 binary aqueous-organic solvents of widely varying 
nucleophilicity and ionizing power values at $25.0{ }^{\circ} \mathrm{C}$. Also listed are the previously published rate data for the sovolysis of propargyl chloroformate (4) [35] at $25.0{ }^{\circ} \mathrm{C}$ and the literature $N_{\mathrm{T}}$ [18-20] and $Y_{\mathrm{Cl}}[13-17]$ values.

Table 1. Specific rates of solvolysis $(k)$ of 1 and 4 in several binary solvents at $25.0^{\circ} \mathrm{C}$ and literature values for $\left(N_{T}\right)$ and $\left(Y_{C l}\right)$.

\begin{tabular}{|c|c|c|c|c|c|}
\hline Solvent (\%) ${ }^{a}$ & $\begin{array}{c}1 @ 25.0^{\circ} \mathrm{C} \text {; } \\
10^{5} \mathrm{k}^{-\mathrm{s}^{-1} \mathrm{~b}}\end{array}$ & $\begin{array}{r}4 @ 25.0^{\circ} \mathrm{C} ; \\
10^{5} \mathrm{k}, \mathrm{s}^{-1} b, c\end{array}$ & $k_{1} / k_{4}$ & $N_{T}^{d}$ & $Y_{C l}^{e}$ \\
\hline $100 \% \mathrm{MeOH}$ & $34.0 \pm 1.2$ & $63.4 \pm 1.2$ & 0.536 & 0.17 & -1.2 \\
\hline $90 \% \mathrm{MeOH}$ & $74.2 \pm 2.5$ & $123 \pm 3$ & 0.603 & -0.01 & -0.20 \\
\hline $80 \% \mathrm{MeOH}$ & $92.9 \pm 3.7$ & $178 \pm 10$ & 0.522 & -0.06 & 0.67 \\
\hline $100 \% \mathrm{EtOH}$ & $17.6 \pm 0.9$ & $35.0 \pm 0.8$ & 0.503 & 0.37 & -2.50 \\
\hline $90 \% \mathrm{EtOH}$ & $25.6 \pm 1.9$ & $53.9 \pm 1.2$ & 0.474 & 0.16 & -0.90 \\
\hline $80 \% \mathrm{EtOH}$ & $34.2 \pm 1.6$ & $66.7 \pm 1.6$ & 0.513 & 0.00 & 0.00 \\
\hline $90 \%$ Acetone & $1.07 \pm 0.04$ & $2.46 \pm 0.10$ & 0.435 & -0.35 & -2.39 \\
\hline $80 \%$ Acetone & $4.21 \pm 0.20$ & $7.52 \pm 0.22$ & 0.560 & -0.37 & -0.80 \\
\hline $70 \%$ Acetone & $6.77 \pm 0.24$ & & & -0.42 & 0.17 \\
\hline $90 \%$ TFE $(w / w)$ & $0.168 \pm 0.020$ & $0.342 \pm 0.007$ & 0.491 & -2.55 & 2.85 \\
\hline $70 \%$ TFE $(w / w)$ & $3.62 \pm 0.17$ & $4.78 \pm 0.07$ & 0.757 & -1.98 & 2.96 \\
\hline $60 \mathrm{~T}-40 \mathrm{E}$ & $1.84 \pm 0.12$ & $3.31 \pm 0.01$ & 0.556 & -0.94 & 0.63 \\
\hline $40 \mathrm{~T}-60 \mathrm{E}$ & $4.52 \pm 0.21$ & $10.0 \pm 0.2$ & 0.452 & -0.34 & -0.48 \\
\hline 20T-80E & $14.1 \pm 1.4$ & $17.4 \pm 1.0$ & 0.810 & 0.08 & -1.42 \\
\hline 97\%HFIP (w/w) & $0.413 \pm 0.027$ & $0.00116 \pm 0.00009$ & 356 & -5.26 & 5.17 \\
\hline 90\%HFIP (w/w) & $0.625 \pm 0.029$ & $0.0426 \pm 0.0020$ & 14.7 & -3.84 & 4.41 \\
\hline $70 \%$ HFIP (w/w) & $1.47 \pm 0.13$ & $3.52 \pm 0.18^{f}$ & 0.417 & -2.94 & 3.83 \\
\hline $50 \% \mathrm{HFIP}(\mathrm{w} / \mathrm{w})$ & $5.61 \pm 0.25$ & & & -2.49 & 3.80 \\
\hline
\end{tabular}

${ }^{a}$ Substrate concentration of ca. $0.0052 \mathrm{M}$; binary solvents on a volume-volume basis at $25.0^{\circ} \mathrm{C}$, except for TFE- $\mathrm{H}_{2} \mathrm{O}$ and HFIP- $\mathrm{H}_{2} \mathrm{O}$ solvents which are on a weight-weight basis. T-E are TFE-ethanol mixtures; ${ }^{b}$ With associated standard deviation; ${ }^{c}$ Reference [35]; ${ }^{d}$ References [18-20]; ${ }^{e}$ References [13-17]; ${ }^{f}$ Listed erroneously in Table 1 of Reference [35]; the correct value (as here listed) was, however, used in the correlations.

From the data reported for substrate $\mathbf{1}$ in Table 1, one observes that the rates of reaction increase as the water content increases in the aqueous-organic mixtures and with the increase in ethanol (EtOH) content in the TFE-EtOH mixtures. This progression suggests that the solvents nucleophilic component plays an important role at developing transition state.

Also tabulated in Table 1 are the rate ratios $\left(k_{1} / k_{4}\right)$ in the commonly studied solvents. In the binary aqueous methanol $(\mathrm{MeOH}), \mathrm{EtOH}$, acetone, TFE, and TFE-EtOH mixtures, the rate ratio oscillates within the very small range of $0.435-0.810$. On the other hand in the aqueous HFIP mixtures, the trend is completely changed and the magnitude of the range of the rate ratio $\left(k_{1} / k_{4}\right)$ increases exponentially from 0.417 in 70\% HFIP to 356 in 97\% HFIP. Furthermore, an inspection of the kinetic data reveals that $k_{4}>k_{1}$ in MeOH, EtOH, acetone, TFE, TFE-EtOH, and 70\% HFIP, and $k_{1}>>k_{4}$ in 97\% HFIP and 90\% HFIP. This examination of the kinetic rates advances an interpretation that the inductive effect of the propargyl group in $\mathbf{4}$ is dominant in $\mathrm{MeOH}$, EtOH, acetone, TFE, TFE-EtOH, and 70\% HFIP, and that $\mathbf{1}$ and $\mathbf{4}$ must solvolyze by a similar mechanism with solvent nucleophilicity playing a significant 
role in these solvents. On the other hand in 97\% HFIP and 90\% HFIP, both highly ionizing solvents, the electron donating effect of the $\gamma$-methyl group in $\mathbf{1}$ predominates and the mechanism has now changed over to one where there is significant ionization in the transition state which is stabilized due to the presence of the electron supplying $\gamma$-methyl group.

In Table 2, we list the specific rates of solvolysis obtained for 2-methoxyphenyl chloroformate (2) in 17 solvents with broadly differing nucleophilicity and ionizing power values. Also recorded in Table 2 , are the previously published pseudo first-order rate data for phenyl chloroformate $(3)[50,51,53,54]$, 4-methoxyphenyl chloroformate (5) [48,49,53-55], and p-nitrophenyl chloroformate (6) $[24,52,53]$.

Table 2. $k_{2}, k_{3}, k_{5}$, and $k_{6}$, in several binary solvents at $25.0{ }^{\circ} \mathrm{C}$.

\begin{tabular}{|c|c|c|c|c|c|}
\hline Solvent (\%) ${ }^{a}$ & $\begin{array}{c}2 @ 25.0^{\circ} \mathrm{C} \text {; } \\
10^{5} \mathrm{k}^{-1} \mathrm{~s}^{-1 b}\end{array}$ & $\begin{array}{c}3 @ 25.0^{\circ} \mathrm{C} ; \\
10^{5} k, \mathrm{~s}^{-1 b, c}\end{array}$ & $\begin{array}{c}5 @ 25.0^{\circ} \mathrm{C} \text {; } \\
10^{5} \mathrm{k}, \mathrm{s}^{-1} b, d\end{array}$ & $k_{5} / k_{2}$ & $\begin{array}{c}6 @ 25.0^{\circ} \mathrm{C} ; \\
10^{5} \mathrm{k}, \mathrm{s}^{-1} \mathrm{~b}, \mathrm{e}\end{array}$ \\
\hline $100 \% \mathrm{MeOH}$ & $127 \pm 17$ & $695 \pm 9$ & $414^{g}$ & 3.25 & $13500^{h}$ \\
\hline $90 \% \mathrm{MeOH}$ & $226 \pm 14$ & $1290^{f}$ & $800^{g}$ & 3.54 & $22700^{h}$ \\
\hline $100 \% \mathrm{EtOH}$ & $33.3 \pm 2.7$ & $260 \pm 3$ & $153 \pm 4$ & 4.59 & $5570^{h}$ \\
\hline $90 \% \mathrm{EtOH}$ & $59.7 \pm 2.4$ & $389 \pm 6$ & $239^{g}$ & 4.00 & $11800^{h}$ \\
\hline $80 \% \mathrm{EtOH}$ & $76.3 \pm 1.9$ & $503 \pm 11$ & $318^{g}$ & 4.17 & $13900^{h}$ \\
\hline $90 \%$ Acetone & $2.47 \pm 0.13$ & $23.8 \pm 1.4$ & $15.0 \pm 0.6$ & 6.07 & \\
\hline $80 \%$ Acetone & $7.83 \pm 0.17$ & $68.8 \pm 0.8$ & $41.5^{g}$ & 5.30 & $2050^{h}$ \\
\hline $70 \%$ Acetone & $26.6 \pm 0.82$ & $125^{f}$ & $77.4^{g}$ & 2.91 & $3190^{h}$ \\
\hline $97 \%$ TFE $(w / w)$ & $0.0605 \pm 0.0021$ & $0.0570 \pm 0.0030$ & $0.0300 \pm 0.0013$ & 0.492 & $0.113 \pm 0.008$ \\
\hline $90 \%$ TFE $(w / w)$ & $0.976 \pm 0.019$ & $1.15 \pm 0.08$ & $0.825 \pm 0.032$ & 0.845 & $8.87 \pm 0.28$ \\
\hline $70 \% \mathrm{TFE}(\mathrm{w} / \mathrm{w})$ & $9.43 \pm 0.24$ & $17.4 \pm 1.3$ & $15.2 \pm 0.6$ & 1.61 & $153 \pm 1.5$ \\
\hline $50 \%$ TFE $(w / w)$ & $33.7 \pm 1.1$ & $63.5 \pm 3.0$ & $52.6 \pm 2.8$ & 1.56 & $438 \pm 44$ \\
\hline $60 \mathrm{~T}-40 \mathrm{E}$ & $6.39 \pm 0.22$ & $19.9 \pm 0.5$ & $17.0 \pm 0.5$ & 2.66 & \\
\hline $40 \mathrm{~T}-60 \mathrm{E}$ & $32.7 \pm 1.2$ & $57.7 \pm 1.9$ & $59.2 \pm 2.3$ & 1.81 & \\
\hline $90 \% \mathrm{HFIP}(\mathrm{w} / \mathrm{w})$ & $0.258 \pm 0.018$ & $0.166 \pm 0.004$ & $0.175 \pm 0.007$ & 0.678 & $1.20 \pm 0.06$ \\
\hline $70 \%$ HFIP (w/w) & $6.48 \pm 0.20$ & $10.5 \pm 0.3$ & $7.58 \pm 0.22$ & 1.17 & $83.8 \pm 0.9$ \\
\hline $50 \%$ HFIP $(w / w)$ & $30.5 \pm 0.18$ & $31.6 \pm 0.6$ & $24.9 \pm 0.5$ & 0.816 & $277 \pm 2$ \\
\hline
\end{tabular}

${ }^{a}$ Substrate concentration of ca. $0.0052 \mathrm{M}$; binary solvents on a volume-volume basis at $25.0^{\circ} \mathrm{C}$, except for TFE- $\mathrm{H}_{2} \mathrm{O}$ and HFIP- $\mathrm{H}_{2} \mathrm{O}$ solvents which are on a weight-weight basis. T-E are TFE-ethanol mixtures; ${ }^{b}$ With associated standard deviation; ${ }^{c}$ References [50,54]; ${ }^{d}$ References [54,55]; ${ }^{e}$ Reference [24]; ${ }^{f}$ References [51,53]; ${ }^{g}$ References [48,49,53]; ${ }^{h}$ References [52,53].

An inspection of the kinetic data for $\mathbf{2}$ displays a tendency of the rates of solvolysis to increase with the addition of water to the aqueous organic mixtures, or with an increase in ethanol content in the TFE-EtOH mixtures. This observation also steers us towards a mechanism where solvent nucleophilicity plays a greater role in the rate determining step.

A comparison of the specific rates of solvolysis of $\mathbf{2 , 3}, \mathbf{5}$, and $\mathbf{6}$, shown in Table 2, exposes a rate trend where $k_{6}>>k_{3}>k_{5}>k_{2}$ in the aqueous methanol, ethanol, and acetone solvents. This rate direction suggests that the inductive effect of the phenoxy group is further greatly enhanced by the presence of a strongly deactivating nitro group in the para position in $\mathbf{6}$ making the carbonyl carbon highly susceptible to nucleophilic attack. PhOCOCl (3) is much faster than its methoxy-substituted analogs $\mathbf{2}$ and $\mathbf{5}$ in the more nucleophilic aqueous $\mathrm{MeOH}, \mathrm{EtOH}$, and acetone solvents, as the methoxy 
group can be electron-withdrawing inductively or electron-donating due to resonance. In these solvents, the rate data indicates that the methoxy group exhibits much greater electron withdrawing character in $\mathbf{2}$ and $\mathbf{5}$, and is more efficient inductively in $\mathbf{5}$ due to a through-space (field) effect.

In the strongly hydrogen bonding solvent $97 \% \mathrm{TFE}$, the rate trends orient differently to $k_{6}>k_{2} \geq k_{3}>k_{5}$. This suggests that in 97\% TFE, the magnitude of the decrease in the inductive abilities of the para substituents in $\mathbf{6}$ and $\mathbf{5}$ is in all probability due to the presence of intermolecular hydrogen bonding between the solvent (TFE) and the oxygen atom(s) in the methoxy groups in $\mathbf{5}$ and in the nitro group in $\mathbf{6}$.

In Table 3, we report the G-W analyses for substrates 1-6 using Equation 2 and employing the $N_{\mathrm{T}}$ [18-20] and $Y_{\mathrm{Cl}}$ scales [13-17]. For 1 in all the 18 solvents studied, we report an $l$ value of $0.78 \pm 0.18$, a $m$ value of $0.31 \pm 0.12$, and an intercept $(c)$ of $-0.15 \pm 0.17$. The correlation coefficient $R=0.832$ and $F$-test $=17$ is rather poor for such an analysis and is indicative of a superimposed mechanism occurring within the solvents. As mentioned earlier, trends in the rate data of $\mathbf{1}$ led us to conclude that this mechanistic change occurs in the highly ionizing HFIP mixtures. Removal of the four aqueous HFIP data points ( $n=14$ solvents), leads to a $l$ value of $1.50 \pm 0.15$, a $m$ value of $0.49 \pm 0.08, c=0.15 \pm 0.10$, and very much improved $R$ and $F$-test values of 0.956 and 58 respectively.

Table 3. Correlation of the specific rates of reaction of 1-6 using Equation 2.

\begin{tabular}{|c|c|c|c|c|c|c|c|}
\hline Substrate & $n^{a}$ & $l^{b}$ & $m^{b}$ & $l / m$ & $c^{c}$ & $R^{d}$ & $F^{e}$ \\
\hline \multirow[t]{3}{*}{1} & 18 & $0.78 \pm 0.18$ & $0.31 \pm 0.12$ & 2.52 & $-0.15 \pm 0.17$ & 0.832 & 17 \\
\hline & $14^{f}$ & $1.50 \pm 0.15$ & $0.49 \pm 0.08$ & 3.06 & $0.15 \pm 0.10$ & 0.956 & 58 \\
\hline & $13^{f, g}$ & $1.52 \pm 0.14$ & $0.51 \pm 0.07$ & 2.98 & $0.18 \pm 0.10$ & 0.963 & 63 \\
\hline 2 & 17 & $1.44 \pm 0.16$ & $0.61 \pm 0.10$ & 2.36 & $0.32 \pm 0.14$ & 0.941 & 54 \\
\hline \multirow[t]{2}{*}{3} & $49^{h}$ & $1.66 \pm 0.05$ & $0.56 \pm 0.03$ & 2.96 & $0.15 \pm 0.07$ & 0.980 & 568 \\
\hline & $17^{i}$ & $1.58 \pm 0.17$ & $0.54 \pm 0.10$ & 2.93 & $0.21 \pm 0.15$ & 0.958 & 79 \\
\hline \multirow[t]{2}{*}{4} & 22 & $1.37 \pm 0.10$ & $0.47 \pm 0.07$ & 2.91 & $0.11 \pm 0.11$ & 0.970 & 152 \\
\hline & $13^{f, g}$ & $1.49 \pm 0.13$ & $0.48 \pm 0.07$ & 3.10 & $0.14 \pm 0.09$ & 0.969 & 77 \\
\hline \multirow[t]{2}{*}{5} & $44^{j}$ & $1.60 \pm 0.05$ & $0.57 \pm 0.05$ & 2.81 & $0.18 \pm 0.06$ & 0.981 & 517 \\
\hline & $17^{i}$ & $1.60 \pm 0.17$ & $0.57 \pm 0.10$ & 2.81 & $0.26 \pm 0.15$ & 0.958 & 78 \\
\hline 6 & $39^{k}$ & $1.68 \pm 0.06$ & $0.46 \pm 0.04$ & 3.65 & $0.074 \pm 0.08$ & 0.976 & 363 \\
\hline
\end{tabular}

${ }^{a} n$ is the number of solvents; ${ }^{b}$ With associated standard error; ${ }^{c}$ Accompanied by standard error of the estimate; ${ }^{d}$ Correlation coefficient; ${ }^{e}$ F-test value; ${ }^{f}$ No HFIP (aq) mixtures; ${ }^{g}$ To compare with 1 and 4 in common identical solvents; ${ }^{h}$ References [50,54]; ${ }^{i}$ To compare with $\mathbf{2}$ in common identical solvents; ${ }^{j}$ Reference [55]; ${ }^{k}$ Reference [24].

A plot of $\log \left(k / k_{\mathrm{o}}\right)_{1}$ against $1.50 N_{\mathrm{T}}+0.49 Y_{\mathrm{Cl}}$ is shown in Figure 2. The four HFIP points (97-50\% HFIP) were not included in the correlation but were added in the figure to show the extent of their deviation. In the remaining 14 solvents, the $l / m$ ratio of 3.06 observed is very similar to the 2.96 reported for $\mathbf{3}$ in 49 solvents. This leads us to believe that $\mathbf{1}$ like $\mathbf{3}$ solvolyzes by an addition-elimination mechanism with a rate-determining addition step in the aqueous ethanol, methanol, acetone, TFE, and TFE-EtOH mixtures studied. 
Figure 2. The plot of $\log \left(k / k_{\mathrm{o}}\right)$ for 1 against $1.50 N_{\mathrm{T}}+0.49 Y_{\mathrm{Cl}}$.

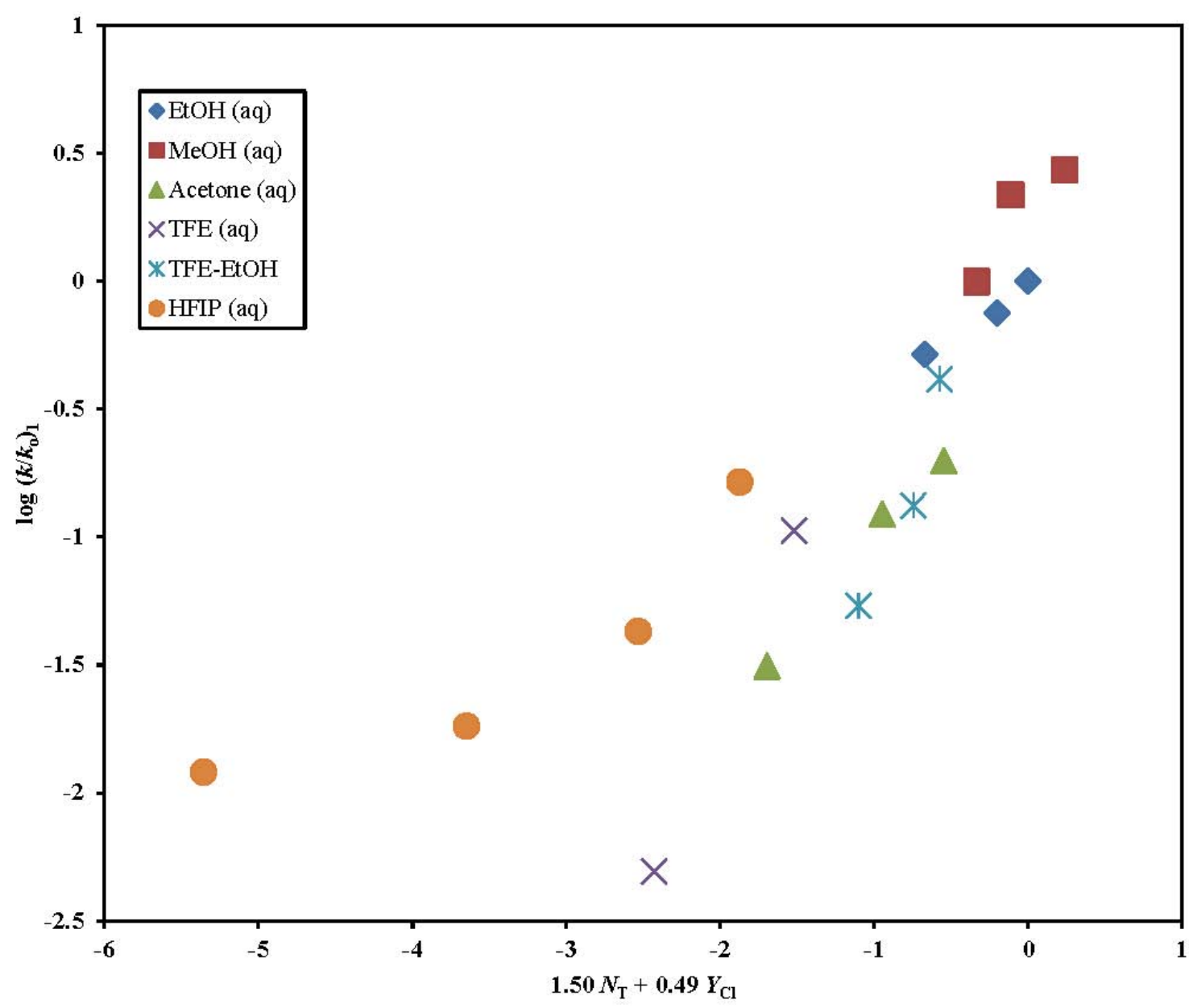

There are 13 common identical solvents (excluding the HFIP mixtures) in which substrates 2-butyn-1-yl chloroformate (1) and propargyl chloroformate (4) were investigated at $25.0{ }^{\circ} \mathrm{C}$. For $\mathbf{1}$ and $\mathbf{4}$, the similarity of mechanism in the thirteen identical solvents is confirmed by the good linear plot of $\log$ $\left(k / k_{\mathrm{o}}\right)_{1}$ against $\log \left(k / k_{\mathrm{o}}\right)_{4}$ shown in Figure 3. The excellent linearity of the plot is affirmed by the goodness-of-fit parameters with a multiple correlation coefficient $(R)$ of 0.995 , an F-test value of 1075, a slope of $1.01 \pm 0.03$, and an intercept of $0.03 \pm 0.03$. The $l / m$ ratio of 2.98 for 1 and 3.10 for 4 is strongly indicative of an analogous rate-determining formation of a tetrahedral intermediate in the 13 common solvents.

Aforementioned the observation that $k_{1}>>k_{4}$ occurs in the $97 \%$ and $90 \%$ HFIP mixtures that exhibit strong hydrogen bonding, is characteristic of a unimolecular ionization transition state which materializes due to the presence of the electron-donating $\gamma$-methyl group in $\mathbf{1}$. The second observation that the specific rates of reaction of $\mathbf{1}$ increase with the increase in water content in aqueous HFIP solvents is similar to the progressions seen for the ionization-type mechanisms witnessed in the HFIP mixtures in other alkyl [12,36,68-70] and alkenyl [37] chloroformate esters. This rate trend denotes that the developing unimoleular carbocation is stabilized by strong rear-side nucleophilic solvation. 
Figure 3. The plot of $\log \left(k / k_{0}\right) \mathbf{1}$ against the $\log \left(k / k_{\mathrm{o}}\right)$ values of $\mathbf{4}$ in the binary aqueous mixtures of EtOH, $\mathrm{MeOH}$, acetone, TFE, and TFE-EtOH.

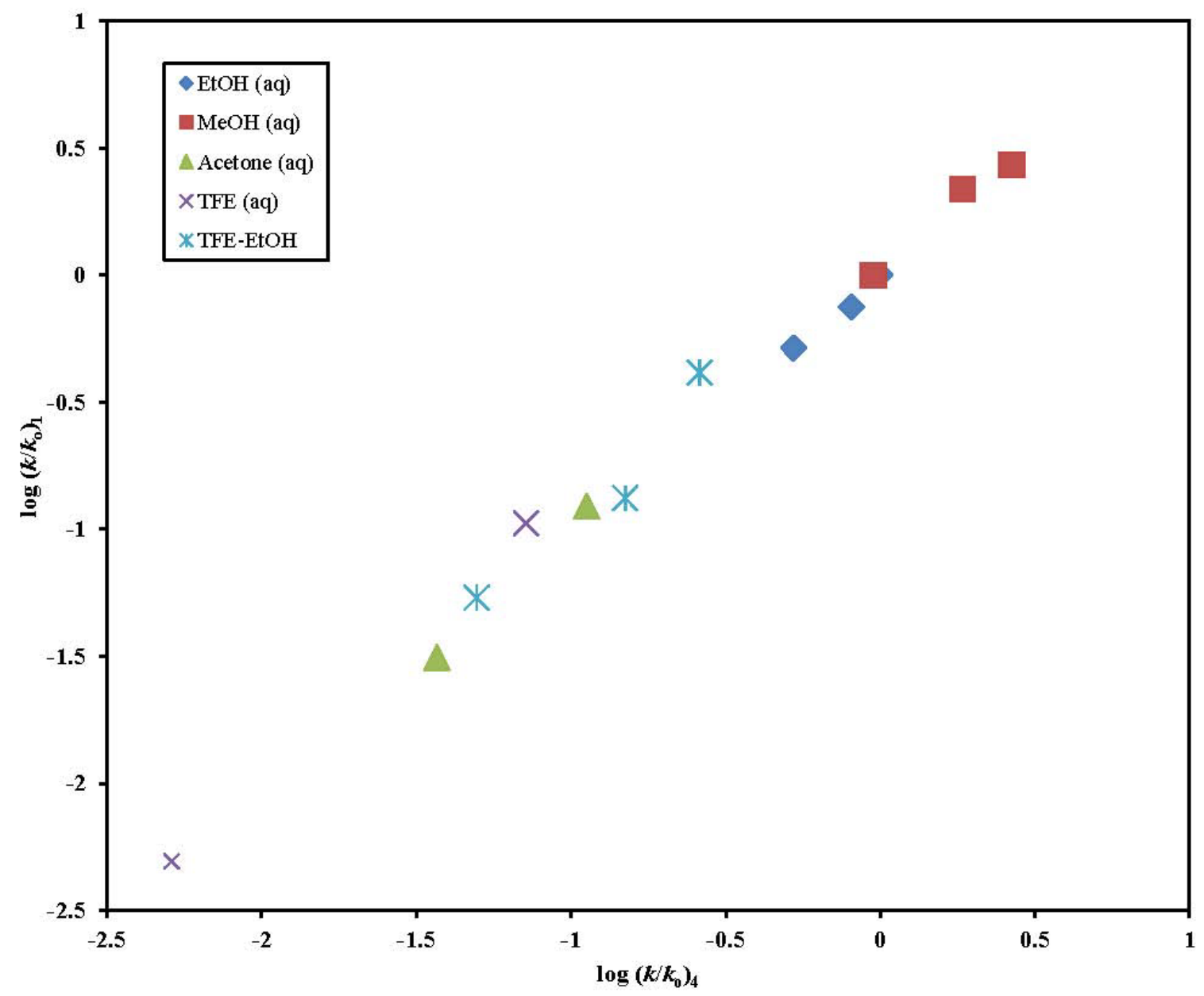

For the $70 \%$ HFIP mixture, the $k_{1} / k_{4}$ ratio falls to 0.42 , a similar value to that observed for solvolyses in mixtures of water with methanol, ethanol, and acetone. This suggests a changeover from the ionization mechanism indicated in solvents richer in HFIP to the addition-elimination pathway.

Using the LFER relationship $\log \left(k / k_{\mathrm{o}}\right)_{1}=1.50 N_{\mathrm{T}}+0.49 Y_{\mathrm{Cl}}+0.15(l, m$, and $c$ values from Table 3$)$, we calculated the rate measurements for the HFIP mixtures that would be expected if 1 strictly followed the bimolecular addition-elimination pathway in these solvents. Our computations resulted in values of $2.12 \times 10^{-9}, 1.22 \times 10^{-7}, 1.41 \times 10^{-6}$, and $6.46 \times 10^{-6}$, for 97, 90, 70, and 50\% HFIP respectively. From a comparison of these calculated values to those experimentally determined and reported in Table 1, one can calculate the corresponding \% ionization values for $\mathbf{1}$ in 97, 90, 70, and 50\% HFIP. These are determined to be $100 \%, 98 \%, 10 \%$, and $12 \%$ respectively.

As shown in the 3-D image 1' for the syn conformer of $\mathbf{1}$ in Figure 4, the electron-supplying ability of the $\gamma$-methyl group on the $\beta$-alkyne in $\mathbf{1}$ is very much reduced since this alkynyl group is twisted out of the plane of the ester oxygen due to the presence of the methylene carbon. It is due to this orientation of the groups in space that the ionization pathway remains dominant only in the very strongly hydrogen bonding 97 and 90\% HFIP mixtures. 
Figure 4. The 3-D images for the syn conformers of 2-butyn-1-yl chloroformate (1'), 2-methoxyphenyl chloroformate (2'), 4-methoxyphenyl chloroformate (5'), and 4-nitrophenyl chloroformate $\left(6^{\prime}\right)$.

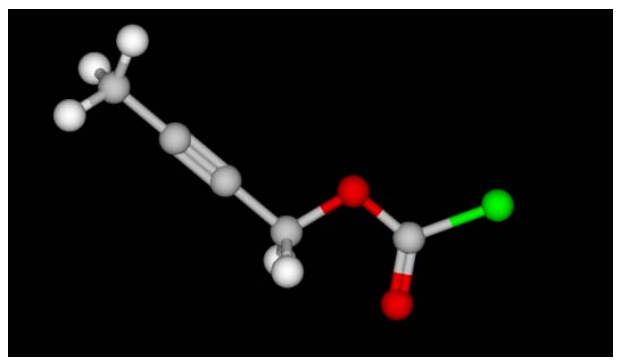

$1^{\prime}$

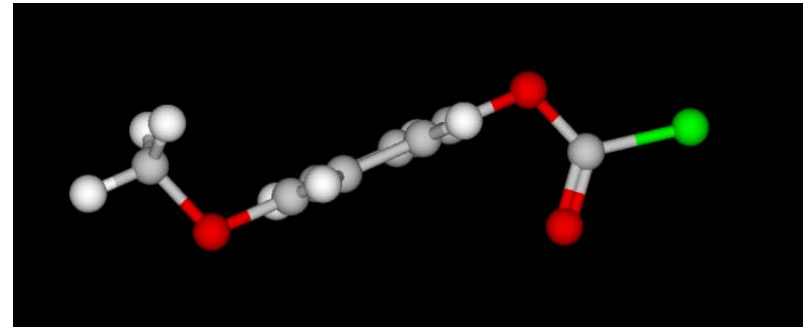

$\mathbf{5}^{\prime}$

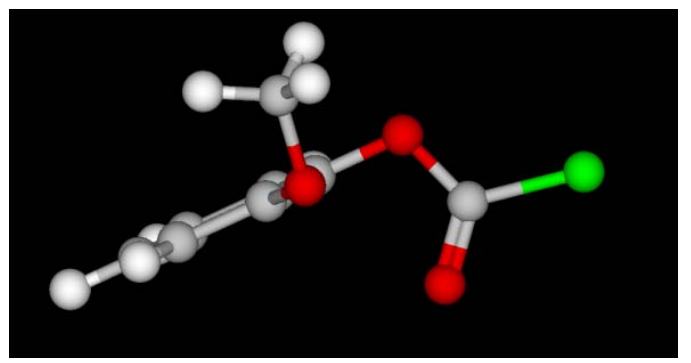

$\mathbf{2}^{\prime}$

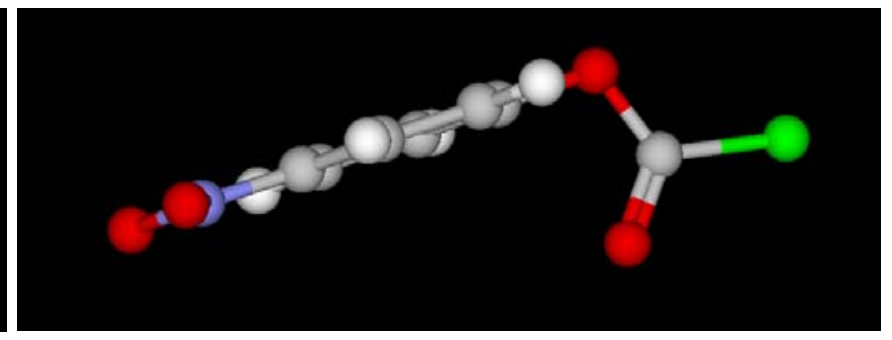

$\mathbf{6}^{\prime}$

For o-methoxyphenyl chloroformate (2), the G-W analyses (Table 3) in the 17 solvents studied resulted in $l=1.44 \pm 0.16, m=0.61 \pm 0.10, c=0.32 \pm 0.14, R=0.941$, and $F$-test $=54$. The slightly inferior correlation seen in the G-W analyses of 2 can be explained by the dual competing mesomeric and inductive effects operating simultaneously at the ortho position of 2 . A plot of $\log \left(k / k_{\mathrm{o}}\right)_{2}$ against $1.44 N_{\mathrm{T}}+0.61 Y_{\mathrm{Cl}}$ that is shown in Figure 5 does show a slight scatter with the highly ionizing aqueous HFIP mixtures lying slightly above the regression line. Removal of the three HFIP points results in $l=1.49 \pm 0.12, m=0.55 \pm 0.07$, an $l / m$ ratio of $2.71, c=0.30 \pm 0.10, R=0.972$, and an improved $F$-test value of 93 in the remaining 14 solvents.

For all of the 17 solvents that 2 was studied in, the observed $l / m$ ratio of 2.36 falls within the range that is typically observed in the solvolyses of chloroformate esters $[12,21,22-26,28-39,41,42,50,54$, 55,68-70] where the addition-elimination pathway with rate determining addition predominates. We also list in Table 3 the previously published $\mathrm{l} / \mathrm{m}$ ratios of 2.96 for phenyl chloroformate $(3)[50,54]$, 2.81 for $p$-methoxyphenyl chloroformate (5) [55], and 3.65 for $p$-nitrophenyl chloroformate (6) [24], in 49,44 , and 39 solvents respectively.

The $l / m$ ratios of $\mathbf{3}$ and $\mathbf{5}$ in the identical 17 solvents that $\mathbf{2}$ was analyzed in, are, 2.93 and 2.81 respectively (Table 3). The gradual receding seen in the $l / m$ ratio going from 2.93 in $\mathbf{3}$, to 2.81 in $\mathbf{5}$, and then to 2.36 in $\mathbf{2}$, is befitting of the decrease in inductive ability and a decrease in the importance of general base catalysis in going from $\mathbf{3}$ to 5 to 2 .

Also reported in Table 2 are the rate ratios $k_{\mathbf{5}} / k_{\mathbf{2}}$ in the 17 common solvents. In methanol, ethanol, and acetone, these ratios range from 2.91 at the low end to 6.07 in the polar aprotic $90 \%$ acetone. As explained earlier, such differences in rate ratios are consistent with the earlier suggestion that the methoxy group in substrate $\mathbf{5}$ exhibits an increased inductive capacity. Also in these nucleophilic solvents steric effects could account for the fact that $\mathbf{2}$ is slower than $\mathbf{5}$. 
Figure 5. The plot of $\log \left(k / k_{\mathrm{o}}\right)$ for 2-methoxyphenyl chloroformate (2) against $1.44 N_{\mathrm{T}}+0.61 Y_{\mathrm{Cl}}$.

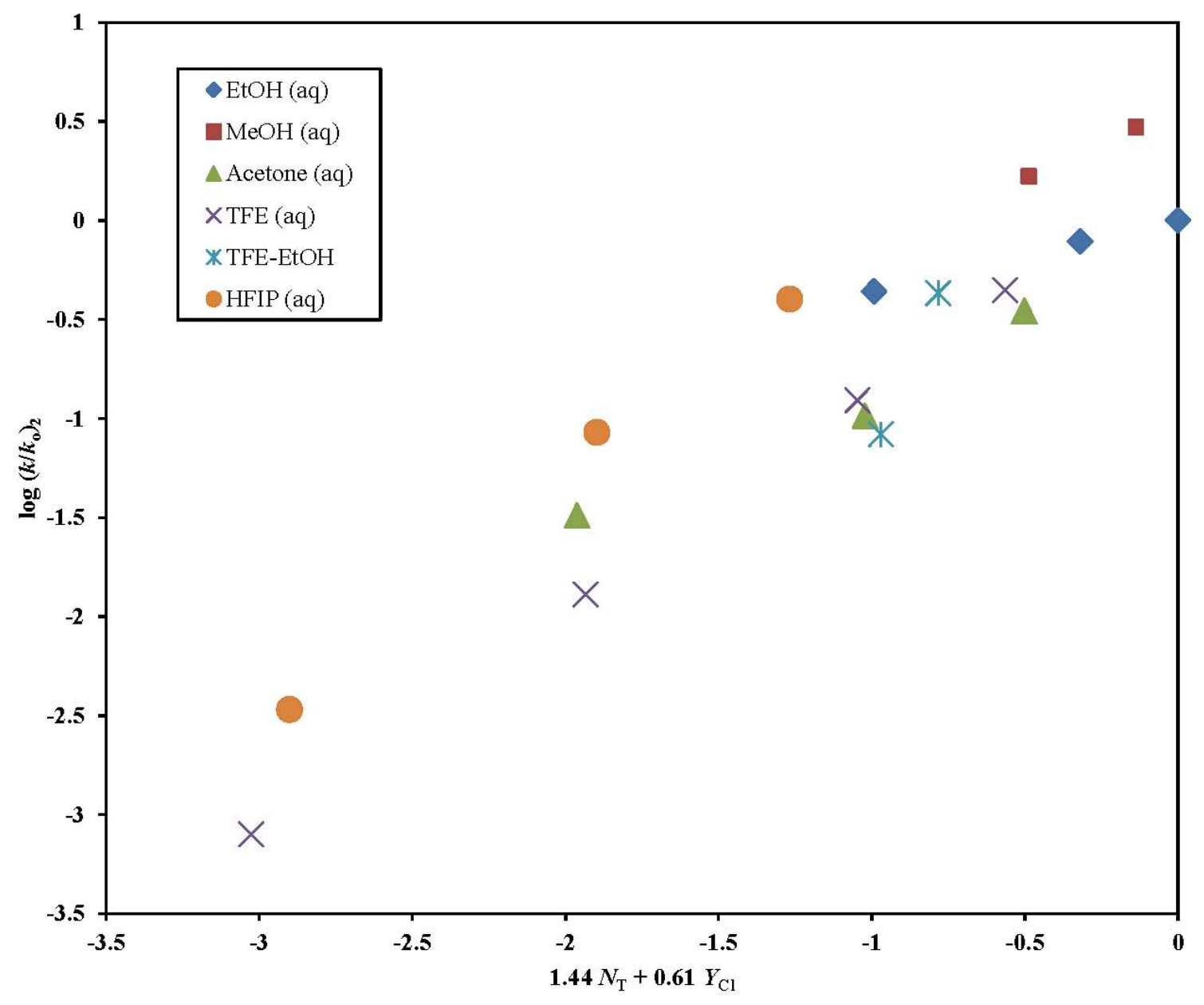

This expansion in the electron-withdrawing character observed when the methoxy group is in the para position in $\mathbf{5}$ is acutely transmitted by the 3-D views of 2-methoxyphenyl chloroformate ( $\left.\mathbf{2}^{\prime}\right)$ and 4-methoxyphenyl chloroformate (5') shown in Figure 4. In the conformer 5', the electron-cloud distribution between the methoxy and the ester oxygens is completely planar and as a result the carbonyl carbon becomes much more electron deficient. This inductive ability of the substituted phenoxy group is further magnified in p-nitrophenyl chloroformate (6) due to the coplanarity of the para-nitro substituent and the ester oxygen, as shown in its conformer $\mathbf{6}^{\prime}$.

On the other hand in the strong hydrogen bonding solvents, especially in 90, 97\% TFE, and 90\% HFIP, the rate trend changes to $k_{2}$ becoming slightly greater than $k_{5}$. This is due to the decrease in the inductive ability of the $p$-methoxy group in $\mathbf{5}$ because of the increased intermolecular hydrogen bond formation between the acidic hydrogen of the solvent group and the oxygen atom of this $p$-methoxy group.

The plot of $\log \left(k / k_{\mathrm{o}}\right)_{2}$ versus $\log \left(k / k_{\mathrm{o}}\right)_{5}$ is shown in Figure 6. In the 17 solvents, there is a good correlation coefficient $(R)$ of $0.975, F$-test of 288 , the slope is $0.778 \pm 0.05$, and the intercept is $0.05 \pm 0.07$. This satisfactory linear correlation further ascertains that $\mathbf{2}$ and $\mathbf{5}$ solvolyze by very similar mechanisms in all the solvents evaluated with a slightly earlier transition state for $\mathbf{2}$. 
Figure 6. The plot of $\log \left(k / k_{0}\right)$ for 2-methoxyphenyl chloroformate (2) against 4-methoxyphenyl chloroformate (5).

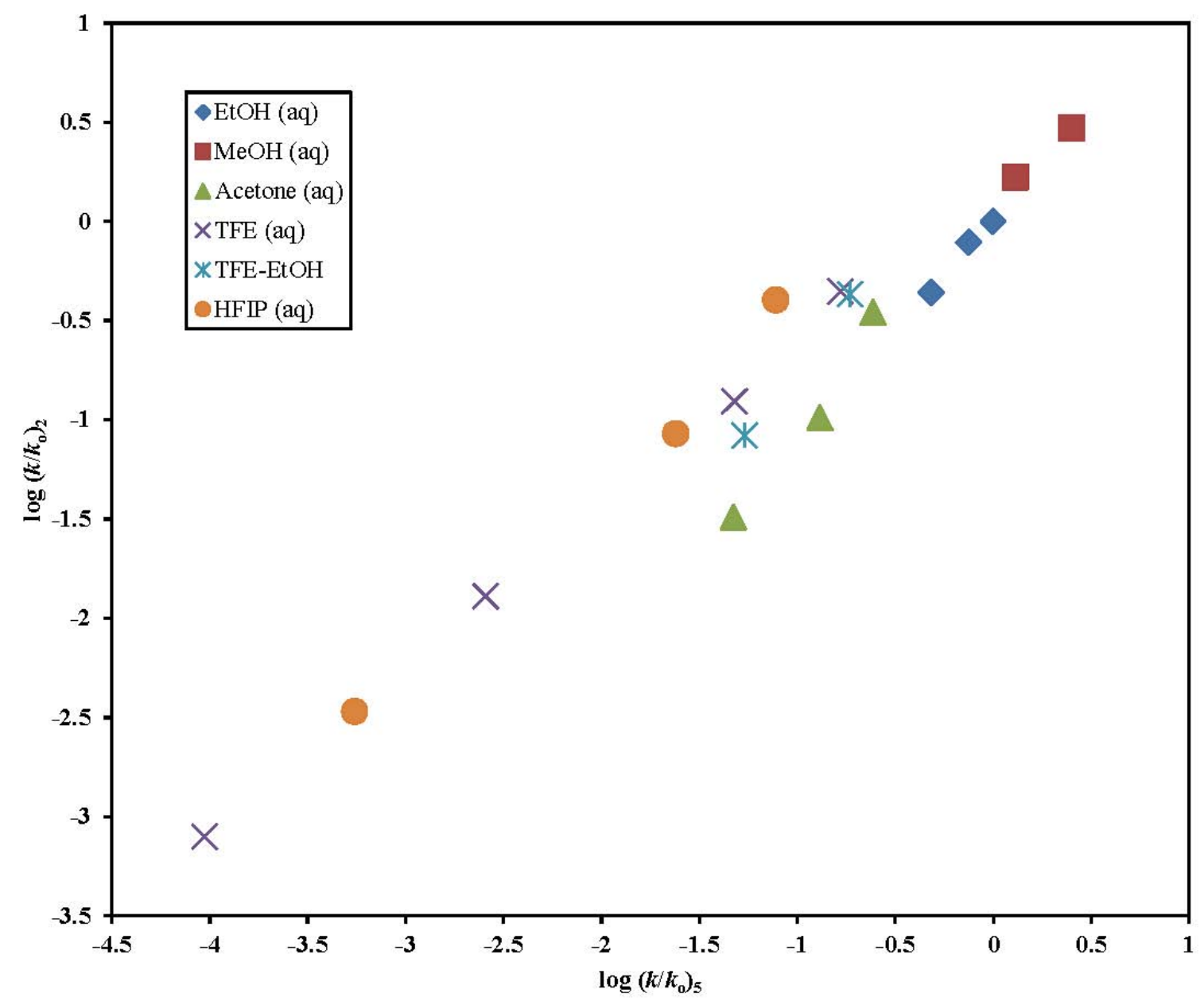

\section{Experimental Section}

The 2-butyn-1-yl chloroformate (98\%) and the 2-methoxyphenyl chloroformate (98\%) were obtained from the Sigma-Aldrich Chemical Company and were used as received. Solvents were purified and the kinetic runs carried out as described previously [12]. A substrate concentration of approximately $0.005 \mathrm{M}$ in a variety of solvents was employed. For some of the runs, calculation of the specific rates of solvolysis (first-order rate coefficients) was carried out by a process in which the conventional Guggenheim treatment [71] was modified [72] so as to give an estimate of the infinity titer, which was then used to calculate for each run a series of integrated rate coefficients. The specific rates and associated standard deviations, as presented in Tables 1 and 2, are obtained by averaging all of the values from, at least, duplicate runs.

Multiple regression analyses were carried out using standard Microsoft statistical packages [73] and calculations for the Guggenheim treatments were performed on commercially available software [74]. The 3-D images presented in Figure 4, were computed using the KnowItAll ${ }^{\circledR}$ Informatics System [75]. 


\section{Conclusions}

Linear free energy relationships such as the G-W equations (Equations 1-4) are simple and useful teaching and practical tools in physical organic chemistry that can be used to interpret and elucidate the solvolytic mechanism of reaction efficiently. In this study, it is demonstrated that 2-butyn-1-yl chloroformate (1) solvolyzes by dual reaction channels in some of the solvents studied. In 14 solvents the addition-elimination dominates and, in the 2 strongly hydrogen bonding HFIP mixtures (97 and 90\% HFIP), the reaction switches over to an ionization channel where the presence of the electron-supplying $\gamma$ methyl group stabilizes the developing carbocation.

The $k_{1} / k_{4}$ ratios of 356 in $97 \%$ HFIP and 15 in $90 \%$ HFIP fall to a value of 0.42 in $70 \%$ HFIP, becoming essentially identical to values in aqueous methanol, ethanol, and acetone and consistent with a switch to an addition-elimination (association-dissociation) mechanism.

In 2-methoxyphenyl chloroformate (2) the inductive and mesomeric effects of the methoxy group compete simultaneously resulting in a slightly inferior G-W plot. The $l / m$ ratio of 2.36 is within the range that would be expected for an aryl chloroformate ester that solvolyzes via a rate-determining addition step in a bimolecular addition-elimination process.

\section{Acknowledgments}

This research was supported by INBRE grant number 2 P2O RR016472-12 from the National Center for Research Resources (NCRR), a component of the National Institutes of Health (NIH); a National Science Foundation (NSF) EPSCoR grant EPS-0814251; a NSF ARI-R2 grant 0960503; and the State of Delaware (DE). The DE-INBRE and DE-EPSCoR grants were obtained through the leadership of the University of Delaware and the authors sincerely appreciate their efforts.

Both undergraduate students, Jaci Knapp and Gabriel Fernandez-Bueno, received DE-INBRE supported Undergraduate Research Assistantships in the Wesley College Directed Research Program in Chemistry [76]. Gabriel Fernandez-Bueno who is a biological chemistry major in the Wesley College Honors Program, also received a NASA/Delaware Space Grant (NNG05GO92H) Undergraduate Tuition Scholarship.

\section{References}

1. Rinehart, J.K. Symmetrical alkynyl ureas. U.S. Patent 4,066,440, 3 January 1978.

2. Hirao, G.; Totani, Y.; Itou, T.; Nakatsuka, M.; Yamaguchi, T. Aromatic chloroformate compound. Jpn. Patent JP3394057, 31 January 2003.

3. Wang, W.; Xu, B.; Hammond, G.B. Synthesis of functionalized $\alpha, \alpha$-disubstituted $\beta$-alkynyl esters from allenoates through an alkynylenolate intermediate. Org. Lett. 2008, 10, 3713-3716.

4. Lepore, S.D.; He, Y.; Damisse, P. Studies on the base-promoted conversion of conjugated alkynyl esters to $\alpha$-substituted $\alpha$-allenyl esters. J. Org. Chem. 2004, 69, 9171-9175.

5. Fathalla, O.A.; Zeid, I.F.; Haiba, M.E.; Soliman, A.M.; Abd-Elmoez, Sh.I.; El-Serwy, W.S. Synthesis, antibacterial and anticancer evaluation of some pyrimidine derivatives. World J. Chem. 2009, 4, 127-132. 
6. Wells, P.R. Linear Free Energy Relationships; Academic Press: New York, NY, USA, 1968; pp. 8-35.

7. Roberts, I.; Johnson, C.D.; Taylor, P.G. Linear free energy and solvolysis reactions. Tetrahedron 1977, 33, 2123-2126.

8. Shorter, J. Correlations Analysis of Organic Reactivity; with Particular Reference to Multiple Regression Analysis; John Wiley \& Sons, Inc.: Somerset, NJ, USA, 1982; pp. 1-235.

9. Winstein, S.; Grunwald, E.; Jones, H.W. The correlation of solvolyses rates and the classification of solvolysis reactions into mechanistic categories. J. Am. Chem. Soc. 1951, 73, 2700-2707, and references there in.

10. Bentley, T.W.; Garley, M.S. Correlations and predictions of solvent effects on reactivity: some limitations of multi-parameter equations and comparisons with similarity models based on one solvent parameter. J. Phys. Org. Chem. 2006, 19, 341-349.

11. Bentley, T.W.; Harris, H.C.; Ryu, Z.-H.; Lim, G.T.; Sung, D.D.; Szajda, S.R. Mechanisms of solvolyses of acid chlorides and chloroformates. Chloroacetyl and phenylacetyl chloride as similarity models. J. Org. Chem. 2005, 70, 8963-8970.

12. Kevill, D.N.; D’Souza, M.J. Sixty years of the Grunwald-Winstein equation: development and recent applications. J. Chem. Res. 2008, 2008, 61-66, and references therein.

13. Bentley, T.W.; Carter, G.E. The $\mathrm{S}_{\mathrm{N}} 2-\mathrm{S}_{\mathrm{N}} 1$ spectrum. 4. Mechanism for solvolyses of tert-butyl chloride: A revised $Y$ scale of solvent ionizing power based on solvolyses of 1-adamantyl chloride. J. Am. Chem. Soc. 1982, 104, 5741-5747.

14. Bentley, T.W.; Llewellyn, G. $Y_{\mathrm{x}}$ scales of solvent ionizing power. Prog. Phys. Org. Chem. 1990, 17, 121-158.

15. Kevill, D.N.; D'Souza, M.J. Additional $Y_{\mathrm{Cl}}$ values and correlation of the specific rates of solvolysis of tert-butyl chloride in terms of $N_{\mathrm{T}}$ and $Y_{\mathrm{Cl}}$ scales. J. Chem. Res. Synop. 1993, 174-175.

16. Lomas, J.S.; D’Souza, M.J.; Kevill, D.N. Extremely large acceleration of the solvolysis of 1-adamantyl chloride upon incorporation of a spiro adamantane substituent: Solvolysis of 1-chlorospiro[adamantane-2, 2'-adamantane]. J. Am. Chem. Soc. 1995, 117, 5891-5892.

17. Kevill, D.N.; Ryu, Z.H. Additional solvent ionizing power values for binary water-1,1,1,3,3,3,hexafluoro-2-propanol solvents. Int. J. Mol. Sci. 2006, 7, 451-455.

18. Schadt, F.L.; Bentley, T.W.; Schleyer, P.v.R. The $\mathrm{S}_{\mathrm{N}} 2-\mathrm{S}_{\mathrm{N}} 1$ spectrum. 2. Quantitative treatments of nucleophilic solvent assistance. A scale of solvent nucleophilicities. J. Am. Chem. Soc. 1976, 98, 7667-7674.

19. Kevill, D.N.; Anderson, S.W. An improved scale of solvent nucleophilicity based on the solvolysis of the S-methyldibenzothiophenium Ion. J. Org. Chem. 1991, 56, 1845-1850.

20. Kevill, D.N. Development and Uses of Scales of Solvent Nucleophilicity. In Advances in Quantitative Structure-Property Relationships; Charton, M., Ed.; JAI Press: Greenwich, CT, USA, 1996; Volume 1, pp. 81-115.

21. D’Souza, M.J.; Ryu, Z.-H.; Park, B.-C.; Kevill, D.N. Correlation of the rates of solvolysis of acetyl chloride and $\alpha$-substituted derivatives. Can. J. Chem. 2008, 86, 359-367.

22. Bentley, T.W. Structural effects on the solvolytic reactivity of carboxylic and sulfonic acid chlorides. Comparisons with gas-phase data for cation formation. J. Org. Chem. 2008, 73, 6251-6257. 
23. D’Souza, M.J.; Yaakoubd, L.; Mlynarski, S.L; Kevill, D.N. Concerted solvent processes for common sulfonyl chloride precursors used in the synthesis of sulfonamide-based drugs. Int. J. Mol. Sci. 2008, 9, 914-925.

24. D’Souza, M.J.; Shuman, K.E.; Carter, S.E.; Kevill, D.N. Extended Grunwald-Winstein analysis-LFER used to gauge solvent effects in p-nitrophenyl chloroformate solvolysis. Int. J. Mol. Sci. 2008, 9, 2231-2242.

25. Ryu, Z.-H.; Lee, S.W.; D’Souza, M.J.; Yaakoubd, L.; Feld, S.E.; Kevill, D.N. Correlation of the rates of solvolysis of two arenesulfonyl chlorides and of trans- $\beta$-styrenesulfonyl chloride-Precursors in the development of new pharmaceuticals. Int. J. Mol. Sci. 2008, 9, 2639-2657.

26. D’Souza, M.J.; Reed, D.N.; Erdman, K.J.; Kyong, J.B.; Kevill, D.N. Grunwald-Winstein analysis - isopropyl chloroformate solvolysis revisited. Int. J. Mol. Sci. 2009, 10, 862-879.

27. Bentley, T.W.; Jones, R.O.; Kang, D.H.; Koo, I.S. The $\mathrm{S}_{\mathrm{N}} 3-\mathrm{S}_{\mathrm{N}} 2$ spectrum. Rate constants and product selectivities for solvolyses of benzenesulfonyl chlorides in aqueous alcohols. J. Phys. Org. Chem. 2009, 22, 799-806.

28. D’Souza, M.J.; Hailey, S.M.; Kevill, D.N. Use of empirical correlations to determine solvent effects in the solvolysis of S-methyl chlorothioformate. Int. J. Mol. Sci. 2010, 11, 2253-2266.

29. D’Souza, M.J.; Mahon, B.P.; Kevill, D.N. Analysis of the nucleophilic solvation effects in isopropyl chlorothioformate solvolysis. Int. J. Mol. Sci. 2010, 11, 2507-2611.

30. Koh, H.J.; Kang, S.J.; Kevill, D.N. Kinetic studies of the solvolyses of 2,2,2-trichloro-1,1dimethylethyl chloroformate. Bull. Korean Chem. Soc. 2010, 31, 835-839.

31. Koh, H.J.; Kang, S.J. Kinetic studies of the solvolyses of isopropenyl chloroformate. Bull. Korean Chem. Soc. 2010, 31, 1793-1796.

32. D'Souza, M.J.; Darrington, A.M.; Kevill, D.N. On the importance of the aromatic ring parameter in studies of the solvolyses of cinnamyl and cinnamoyl halides. Org. Chem. Int. 2010, 2010, doi: $10.1155 / 2010 / 130506$.

33. Moon, D.H.; Seong, M.H.; Kyong, J.B.; Lee, Y.; Lee, Y.-W. Correlation of the rates of solvolysis of 1- and 2-naphthyl chloroformates using the extended Grunwald-Winstein equation. Bull. Korean Chem. Soc. 2011, 32, 2413-2417.

34. D’Souza, M.J.; Carter, S.E.; Kevill, D.N. Correlation of the rates of solvolysis of neopentyl chloroformate-A recommended protecting agent. Int. J. Mol. Sci. 2011, 12, 1161-1174.

35. D’Souza, M.J.; Darrington, A.M.; Kevill, D.N. A study of solvent effects in the solvolysis of propargyl chloroformate. ISRN Org. Chem. 2011, 2011, 767141:1-767141:6.

36. D’Souza, M.J.; McAneny, M.J.; Kevill, D.N.; Kyong, J.B.; Choi, S.H. Kinetic evaluation of the solvolysis of isobutyl chloro- and chlorothioformate esters. Beilstein J. Org. Chem. 2011, 7, 543-552.

37. D’Souza, M.J.; Shuman, K.E.; Omondi, A.O.; Kevill, D.N. Detailed analysis for the solvolysis of isopropenyl chloroformate. Eur. J. Chem. 2011, 2, 130-135.

38. D’Souza, M.J.; Hailey, S.M.; Mahon, B.P.; Kevill, D.N. Understanding solvent effects in the solvolyses of 4-fluorophenyl chlorothionoformate. Chem. Sci. J. 2011, CSJ-35, 1-9.

39. Koh, H.J.; Kang, S.J. A kinetic study on solvolysis of 9-fluorenylmethyl chloroformate. Bull. Korean Chem. Soc. 2011, 32, 3799-3801. 
40. Ruff, F.; Farkas, Ö. Concerted $\mathrm{S}_{\mathrm{N}} 2$ mechanism for the hydrolysis of acid chlorides: Comparisons of reactivities calculated by the density functional theory with experimental data. J. Phys. Org. Chem. 2011, 24, 480-491.

41. Park, K.-H.; Kevill, D.N. Influence of the ortho effect in the solvolyses of dichlorobenzoyl chlorides. J. Phys. Org. Chem. 2011, doi:10.1002/poc.1851.

42. Park, K.-H.; Kevill, D.N. The importance of the ortho effect in the solvolyses of 2,6-difluorobenzoyl chloride. J. Phys. Org. Chem. 2011, doi:10.1002/poc.1906.

43. Bentley, T.W.; Harris, H.C. Solvolyses of benzoyl chlorides in weakly nucleophilic media. Int. J. Mol. Sci. 2011, 12, 4805-4818.

44. Kevill, D.N.; Ismail, N. H.J.; D’Souza, M.J. Solvolysis of the (p-methoxybenzyl)dimethylsulfonium Ion. Development and use of a scale to correct for dispersion in Grunwald-Winstein plots. J. Org. Chem. 1994, 59, 6303-6312.

45. Kevill, D.N.; D’Souza, M.J. Use of the simple and extended Grunwald-Winstein equations in the correlation of the rates of solvolysis of highly hindered tertiary alkyl derivatives. Cur. Org. Chem. 2010, 14, 1037-1049.

46. Queen, A. Kinetics of the hydrolysis of acyl chlorides in pure water. Can. J. Chem. 1967, 45, 1619-1629.

47. Butler, A.R.; Robertson, I.H.; Bacaloglu, R. Kinetics and mechanism of the base-catalysed hydrolysis of some substituted phenyl chloroformates. J. Chem. Soc. Perkin Trans 2 1974, 1733-1736.

48. Yew, K.H.; Koh, H.J.; Lee, H.W.; Lee, I. Nucleophilic substitution reactions of phenyl chloroformate. J. Chem. Soc. Perkin Trans. 2 1995, 2263-2268.

49. Koo, I.S.; Yang, K.; Kang, K.; Oh, H.K.; Lee, I. Stoichiometric solvation effects. Product-rate correlation for the solvolyses of phenyl chloroformate in alcohol-water mixtures. Bull. Korean Chem. Soc. 1996, 17, 520-524.

50. Kevill, D.N.; D'Souza, M.J. Correlation of the rates of solvolysis of phenyl chloroformate. J. Chem. Soc. Perkin Trans. 2 1997, 1721-1724.

51. Koo, I.S.; Yang, K.; Koo, J.C.; Park, J.-K.; Lee, I. Stoichiometric solvation effects. Part 4. Product-Rate correlations for solvolyses of p-methoxyphenyl chloroformate in alcohol-water mixtures. Bull. Korean Chem. Soc. 1997, 18, 1017-1021.

52. Koo, I.S.; Yang, K.; Kang, K.; Lee, I.; Bentley, T.W. Stoichiometric solvation effects. Part 3. Product-Rate correlations for solvolyses of $p$-nitrophenyl chloroformate in alcohol-water mixtures. J. Chem. Soc. Perkin Trans 2 1998, 1179-1183.

53. Koo, I.S.; Yang, K.; Kang, K.; Lee, I. Transition-state variation in the solvolyses of para-substituted phenyl chloroformates in alcohol-water mixtures. Bull. Korean Chem. Soc. 1998, 19, 968-973.

54. Kevill, D.N.; Koyoshi, F.; D'Souza, M.J. Correlation of the specific rates of solvolysis of aromatic carbamoyl chlorides, chloroformates, chlorothionoformates, and chlorodithioformates revisited. Int. J. Mol. Sci. 2007, 8, 346-352.

55. D’Souza, M.J.; Reed, D.; Koyoshi, F.; Kevill, D.N. Consideration of the factors influencing the specific rates of solvolysis of p-methoxyphenyl chloroformate. Int. J. Mol. Sci. 2007, 8, 788-796. 
56. Castro, E.A.; Ruiz, M.G.; Salinas, S.; Santos, J.G. Kinetics and mechanism of the aminolysis of phenyl and 4-nitrophenyl chloroformates in aqueous solution. J. Org. Chem. 1999, 64, 4817-4820.

57. Castro, E.A.; Ruiz, M.G.; Santos, J.G. Structure-reactivity correlations in the aminolysis of aryl chloroformates. Int. J. Chem. Kinetics 2001, 281-287.

58. Crugerias, J.; Leis, J.R.; Ríos, A. Micellar effects on the spontaneous hydrolysis of phenyl chloroformate. J. Chem. Educ. 2001, 78, 1538-1540.

59. Muňoz, M.; Rodríguez, A.; Graciani, M.d.M.; Moyá, M.L. Micellar medium effects on the hydrolysis of phenyl chloroformate in ionic, zwitterionic, nonionic, and mixed micellar solutions. Int. J. Chem. Kinetics 2002, 34, 445-451.

60. Graciani, M.d.M.; Rodríguez, A.; Muňoz, M.; Moyá, M. Water-ethylene glycol alkyltrimethylammonium bromide micellar solutions as reaction media: Study of spontaneous hydrolysis of phenyl chloroformate. Langmuir 2003, 19, 8685-8691.

61. McManus, S.P.; Safavy, A. Solvolysis in mixed solvents with complementary electrophilic and nucleophilic properties. Hexafluoro-2-propanol and 1,3-propanedithiol. J. Org. Chem. 1986, 51, 3532-3535.

62. Doherty, R.M.; Abraham, M.H.; Harris, J.M.; Taft, R.W.; Kamlet, M.J. Linear solvation energy relationships. 39. A double-difference method for estimating electrophilic solvent assistance effects in solvolysis reactions. J. Org. Chem. 1986, 51, 4872-4875.

63. Koo, I.S.; Lee, J.S.; Yang, K.; Kang, K.; Lee, I. The studies on substituent and kinetic solvent isotope effect in solvolyses of phenyl chloroformates. Bull. Korean Chem. Soc. 1999, 20, 573-576.

64. Kim, R.; Ali, D.; Lee, J.P.; Yang, K.; Koo, I.S. Correlation of the rates of solvolysis of 4-morpholinecarbonyl chloride using the extended Grunwald-Winstein equation. Bull. Korean Chem. Soc. 2010, 31, 1963-1967.

65. Choi, H.; Ali, D.; Lee, J.P.; Yang, K.; Park, J.K.; Koo, I.S. Correlation of the rates of solvolysis of 1-piperidincarbonyl chloride using the extended Grunwald-Winstein equation. Bull. Korean Chem. Soc. 2011, 32, 3941-3946.

66. Kevill, D.N.; Casamassa, A.J.; D’Souza, M.J. Rates and product selectivities for the solvolyses of 4-(chloroformyl)morpholine. J. Chem. Res. S. 1996, 472-473.

67. Chemical Compounds Database. Available online: http://www.chembase.com/cbid_84810.htm (accessed on 8 October 2010).

68. Kevill, D.N.; D'Souza, M.J. Concerning the two reaction channels for the solvolyses of ethyl chloroformate and ethyl chlorothioformate. J. Org. Chem. 1998, 63, 2120-2124.

69. Kyong, J.B.; Won, H.; Kevill, D.N. Application of the extended Grunwald-Winstein equation to solvolyses of $n$-propyl chloroformate. Int. J. Mol. Sci. 2005, 6, 87-96.

70. Kevill, D.N.; Kim, J.C.; Kyong, J.B. Correlation of the rates of solvolysis of methyl chloroformate and solvent properties. J. Chem. Res. S. 1999, 150-151.

71. Frost, A.A.; Pearson, R.G. Kinetics and Mechanism-a Study of Homogeneous Chemical Reactions, 2nd Ed.; Wiley: New York, NY, USA, 1961; pp. 49-50.

72. Kevill, D.N.; Abduljaber, M.H. Correlation of the rates of solvolysis of cyclopropylcarbinyl and cyclobutyl bromides using the extended Grunwald-Winstein equation. J. Org. Chem. 2000, 65, 2548-2554.

73. Microsoft Office, Excel 2010; Microsoft Corporation: Redmond, WA, USA, 2010. 
74. SigmaPlot, version 9.0; SYSTAT Software Inc.: San Jose, CA, USA, 2005.

75. KnowItAll ${ }^{\circledR}$ Informatics System, ADME/Tox 2008; BioRad Laboratories, Philadelphia, PA, USA, 2008.

76. D’Souza, M.J.; Dwyer, P.; Allison, B.E.; Miller, J.M.; Drohan, J. Wesley College ignites potential with undergraduate student research program. CUR Quart. 2011, 32, 41-45.

(C) 2012 by the authors; licensee MDPI, Basel, Switzerland. This article is an open access article distributed under the terms and conditions of the Creative Commons Attribution license (http://creativecommons.org/licenses/by/3.0/). 